\title{
I. On the most effective adjustment of an induction-coil
}

\section{E. Taylor Jones D.Sc.}

To cite this article: E. Taylor Jones D.Sc. (1915) I. On the most effective adjustment of an induction-coil , Philosophical Magazine Series 6, 29:169, 1-15, DOI:

10.1080/14786440108635275

To link to this article: http://dx.doi.org/10.1080/14786440108635275

曲 Published online: 08 Apr 2009.

Submit your article to this journal $[\pi$

Џ Article views: 3

Q View related articles $₫$ 
THE

LONDON, EDINBURGH, AND DUBLIN

\title{
PHILOSOPHICAL MAGAZINE
}

\author{
AND \\ JOURNAL OF SCIENCE.
}

[SIXTH SERIES.]

JANUARY 1915.

I. On the most Effective Adjustment of an Induction-coil. By E. TAYLOR JONEs, D.Sc., Professor of Physics in the Unixersity College of North Wales, Bangor* .

[Plnte I.]

T $N$ a recent paper $\dagger$ it was shown that the secondary 1 potential and spark-length developed by an inductioncoil, when a given current is interrupted in the primary circuit, are greatest under the following conditions :-

(1) The ratio $n_{2} / n_{1}$ of the two frequencies of electrical oscillation of the system has one of the values $3,7,11, \ldots \ldots$;

(2) $\mathrm{L}_{1} \mathrm{C}_{1}=\left(1-k^{2}\right) \mathrm{L}_{2} \mathrm{C}_{2} \ddagger$.

The first is the condition that maxima of the two potential waves in the secondary circuit should occur simultaneously, the second that the sum of the amplitudes of the two waves should be a maximum for a given value of $k$.

It was further stated that the most effective of the ratios specitied in (1) is $n_{2} / n_{1}=3$, and that in this case the conditions are satisfied by the adjustment $k=\cdot 756$, $\mathrm{L}_{1} \mathrm{C}_{1}=\cdot 429 \mathrm{~L}_{2} \mathrm{C}_{2}$.

* Communicated by the Author.

+ Phil. Mag. xxvii.pp. 580-586, April 1914.

$\mp \mathrm{L}_{2}, \mathrm{I}_{2}$ are the self-inductances, $\mathbb{C}_{1}, \mathrm{C}_{2}$ the capacities, and $k$ is the coupling coefficient of the primary and secondary circuits.

Phil. Maq. S. 6. Vol. 29. No. 169. Jan. 1915. 
The physical meaning of the above results may be further considered in the light of what goes on in the primary circuit after the interruption of the current. An expression for the potential-difference $V_{3}$ of the plates of the primary condenser, at any time $t$ after the interruption of the current $i_{0}$, has been given by Dibbern *. If the resistances of the circuits are neglected, Dibbern's expression becomes

$$
\begin{aligned}
\mathrm{V}_{1}=\frac{2 \pi i_{0} n_{1} n_{2}^{2}}{\mathrm{C}_{1}\left(n_{2}^{2}-n_{1}^{2}\right)} & \left(\frac{1}{4 \pi^{2} n_{2}^{2}}-\mathrm{L}_{1} \mathrm{C}_{1}\right) \sin 2 \pi n_{1} t \\
& -\frac{2 \pi i_{0} n_{1}^{2} n_{2}}{\mathrm{C}_{1}\left(n_{2}{ }^{2}-n_{1}^{2}\right)}\left(\frac{1}{4 \pi^{2} n_{1}^{2}}-\mathrm{L}_{1} \mathrm{C}_{1}\right) \sin 2 \pi n_{2} t .
\end{aligned}
$$

If $n_{2} / n_{1}$ has one of the values $3,7,11, \ldots$, then at the time $t=1 / 4 n_{1}, \sin 2 \pi n_{1} t=1$, and $\sin 2 \pi n_{2} t=-1$. Consequently the value of $V_{1}$ becomes at this instant

$$
\frac{i_{0}}{2 \pi C_{1}} \cdot \frac{1}{n_{2}-n_{1}}-2 \pi i_{0} L_{1} \cdot \frac{n_{1} n_{2}}{n_{2}-n_{1}} \text {. }
$$

This may be expressed in terms of the ratio $\mathrm{L}_{2} \mathrm{C}_{2} / \mathrm{L}_{1} \mathrm{C}_{1}$. Calling this $m$, and writing $a$ for $\frac{1}{8 \pi^{2} L_{2} \mathrm{C}_{2}\left(1-k^{2}\right)}$, we have

$$
\begin{aligned}
n_{1} n_{2} & =2 a \sqrt{m\left(1-k^{2}\right)}, \\
n_{2}-n_{1} & =\sqrt{\left.2 a(m+1)-4 a \sqrt{m\left(1-k^{2}\right.}\right)}+. \\
\text { Hence } \quad V_{1} & =\frac{i_{0}\left\{1-8 \pi^{2} \mathrm{~L}_{1} \mathrm{C}_{1} a \sqrt{m\left(1-k^{2}\right.}\right)}{2 \pi \mathrm{C}_{1} \sqrt{2 a(m+1)-4 a \sqrt{m\left(1-k^{2}\right)}}} .
\end{aligned}
$$
Inserting the value of $a$ and condition (2), i.e. $m=\frac{1}{1-k^{2}}$,
we find that this expression vanishes.

It appears, therefore, that if conditions (1) and (2) are satisfied, the amplitudes of the two potential waves in the primary circuit are equal, and that at the instant in question the potentials are at their maxima, but in opposite phase. The primary condenser is therefore uncharged, while at the same moment the secondary potential is at its maximum $\ddagger$, the two waves in the secondary circuit being then at their maxima and in the same phase. Further, since $d V_{1} / d t=0$, and $d \mathrm{~V}_{2} / d t=0$, there is no current in either circuit. The whole of the energy therefore exists at this moment in the Kiel.

* E. Dibbern, Ann. d. Physiz, xl. 4, p. 938 (1913); Inaug. Diss., † L. c. p. 581 .

$\ddagger$ L.c. p. 581. 
electrostatic form in the secondary circuit, and the se condary potential must in these circumstances have its greatest possible value for a given initial energy-supply $\frac{1}{2} \mathrm{~L}_{1} i_{0}{ }^{2}$.

It was shown in the previous paper to which reference has been made ${ }^{*}$ that the value of this maximum secondary potential, still on the assumption that the resistances are negligible, is

$$
\begin{aligned}
\mathrm{V}_{2 m} & =i_{0} \cdot \frac{\mathrm{L}_{21}}{\sqrt{\overline{\mathrm{L}_{2} \mathrm{C}_{2}}}} \cdot \frac{1}{k} \ldots . . \\
& =i_{0} \sqrt{\frac{\mathrm{L}_{21}}{\mathrm{~L}_{12}}} \cdot \sqrt{\frac{\mathrm{L}_{1}}{\mathrm{C}_{2}}} \cdot \ldots . .
\end{aligned}
$$

The energy equation is therefore

$$
\frac{1}{2} \mathrm{~L}_{1} i_{0}^{2}=\frac{1}{2} \mathrm{C}_{2} \mathrm{~V}_{2 m}^{2} \cdot \frac{\mathrm{L}_{12}}{\mathrm{~L}_{21}}
$$

The factor $\mathrm{L}_{12} / \mathrm{L}_{21}$ arises from the manner in which the capacity $\mathrm{C}_{2}$ of the secondary circuit is defined. It is the charge on one-half of the secondary coil (and the bodies connected to its terminal), divided by the difference of potential of the terminals. The charge on this portion of the secondary circuit is $\mathrm{C}_{2} \mathrm{~V}_{2 m}$, but as some of this charge is at a lower potential than that of the terminals, the energy must be less than $\frac{1}{2} \mathrm{C}_{2} \mathrm{~V}_{2 m}^{2}$. The correcting factor is $\mathrm{L}_{12} / \mathrm{L}_{21}$.

There are many values of $k$ and $\mathrm{L}_{1} \mathrm{C}_{1} / \mathrm{L}_{2} \mathrm{C}_{2}$ which satisfy the above conditions. The first four, probably the only ones having any practical importance, are given in Table I.

TABLE I.

\begin{tabular}{|c|c|c|}
\hline$n_{2} / n_{1} \cdot$ & $k \cdot$ & $\frac{\mathrm{L}_{1} \mathrm{C}_{2}}{\mathrm{~L}_{2} \mathrm{C}_{2}}=1-k^{2} \cdot$ \\
\hline 3 & $\cdot 756$ & $\cdot 429$ \\
7 & $\cdot 914$ & $\cdot 164$ \\
11 & .950 & $\cdot 098$ \\
15 & $\cdot 965$ & $\cdot 070$ \\
\hline
\end{tabular}

If we define the efficiency of an induction-coil as the ratio of the maximum electrostatic energy in the secondary to the electrokinetic energy in the primary cirenit just before the interruption of the current $\left(i . e ., \frac{1}{2} L_{1} i_{0}{ }^{2}\right)$, then the efficiency

* L. c. pp. 581,584 . 
is unity in each of the adjustments specified in Table $I$. if the resistances of the circuits are negligible. But it is easy to see that of these adjustments the first (i.e., $n_{2} / n_{1}=3$, $\left.\mathrm{I}_{1} \mathrm{C}_{1}=\cdot 429 \mathrm{~L}_{2} \mathrm{C}_{2}\right)$ is the one which gives the longest spark for a given primary current. For let us suppose that an induction-coil is so constructed, and the primary condenser so chosen, that $k=\cdot 914$ and $\mathrm{L}_{1} \mathrm{C}_{1}=\cdot 164 \mathrm{~L}_{2} \mathrm{C}_{2}$. This is the second adjustment of Table I., and it allows the whole of the primary energy $\frac{1}{2} \mathrm{~L}_{1} i_{0}{ }^{2}$ to be converted at a certain moment after the interruption into electrostatic energy in the secondary circuit. Now by inserting coils of suitable self-inductance, say $l_{1}$, in the primary circuit (coils which do not act inductively on the induction-coil) we can reduce the coupling coefficient to $\cdot 756$; and if the primary condenser is chosen so that $\left(\mathrm{I}_{1}+l_{1}\right) \mathrm{C}_{1}=\cdot 429 \mathrm{I}_{2} \mathrm{C}_{2}$, we then have the first adjustment, with $n_{2} / n_{1}=3$. The system has again unit efficiency, but the maximum electrostatic energy in the secondary is now $\frac{1}{2}\left(\mathrm{~L}_{1}+l_{1}\right) i_{0}^{2}$, and is greater than the former value in the ratio of $\mathrm{L}_{1}+l_{1}$ to $\mathrm{L}_{1}$. The capacity $\mathrm{C}_{2}$ of the secondary coil being unaltered, the secondary potential is increased in the ratio $\sqrt{\mathrm{L}_{1}+l_{1}}$ to $\sqrt{\mathrm{L}_{1}}$. The $3 / 1$ adjustment is thus more effective (though not more efficient) than the others because it allows a greater quantity of initial energy to be converted into electrostatic energy in the secondary circuit, in which therefore the charge and potential developed are greater than in the other cases.

There are other ways in which the coupling coefficient could be reduced (e.g., from $\cdot 914$ to $\cdot 756$ ), but none of them are so effective as the plan of introducing external inductance into the primary circuit. For instance*, external inductance may be introduced in the secondary circuit. This increases $\mathrm{C}_{2}$, and to some extent $\mathrm{L}_{12}$, without altering $\mathrm{L}_{1}$ and $\mathrm{L}_{21}$, and therefore, by $(3 b)$, lowers the secondary potential. Again, $k$ may be reduced by removing a part of the iron core. This diminishes $I_{1}$ without causing any increase in $\mathrm{L}_{21} / \mathrm{L}_{12}$, or any change in $\mathrm{C}_{2}$, and therefore, by $(3 b)$, reduces $\mathrm{V}_{2 m}$. The reduction of the coupling may also be effected by withdrawing the primary coil with the core to a suitable distance along the axis of the secondary. This process reduces $\mathrm{L}_{12}, \mathrm{~L}_{21}$, and $L_{2}$, without changing $L_{1}$, and should cause no change in the secondary potential except such as may be due to a slight diminution of $\mathrm{C}_{2}$ or of the ratio $\mathrm{L}_{21} / \mathrm{L}_{12}$.

It should be clearly understood that these reductions of the coupling are supposed to bring the system from

* In each of these supposed modifications the primary capacity is to be adjusted so that $\mathrm{L}_{1} \mathrm{C}_{1}=\left(1-k^{2}\right) \mathrm{L}_{2} \mathrm{C}_{2}$. 
one state of unit efficiency to another, e. $g$. from the second to the first adjustment of Table $I$., for it is only in these states that equations $(3 a),(3 b)$ hold. If, on the other hand, $k$ lies between two of the unit-efficiency values, the spark-length for a given current may be increased by withdrawing the primary coil and core to a suitable distance along the axis of the secondary. For example, the coil with which I have experimented has a coupling coefficient of $\cdot 876$, and the longest spark occurs when the primary capacity is about .06 microfarad*. A marked increase is, however, produced in the spark-length by withdrawing the primary coil and core to a distance of $36.5 \mathrm{~cm}$. from its nearly symmetrical position in the secondary, and increasing the capacity to 15 microfarad.

We may conclude that auy induction-coil in which the coupling is greater than 756 can be improved in sparklength by connecting external series inductance in the primary circuit so as to reduce the coupling to this value. An induction-coil should not be constructed so that the coupling is less than $\cdot 756$, for there is no convenient way of increasing the coupling to this value. Nor should tho coupling coeficient of the primary and secondary coils have precisely this value, though if no external coils are used this is the best arrangement. Better effects are obtained by coupling the coils more closely than this, and adding series inductance to the primary circuit so as to reduce $k$ to this value. The ratio $\mathrm{L}_{1} / \mathrm{C}_{2}$ is thereby increased, and it is upon this quantity, when the adjustments (1) and (2) are effected, that the maximum secondary potential for a given primary current chiefly depends.

In fig. 1 (A) are shown curves representing the two potential waves in the primary circuit of an induction-coil in which the above adjustment has boen effected, and in which the damping of the oscillations is negligible. The amplitude of each wave is taken as 5000 volts, and the periods are $\cdot 0024 \mathrm{sec}$. and $\cdot 0008$ sec. These values are chosen so as to correspond approximately (for $i_{0}=10$ amperes) with those found in an actual case, as described below. Fig. 1 (B) shows the result of superposing the two curves of (A). The equation to curve $(B)$, the ordinate of which represents the potential of the primary condenser $t$ seconds after the interruption, is

$$
\mathrm{V}_{1}=-5000 \sin 150,000 t-5000 \sin 450,000 t \text {, }
$$

the angles being given in degrees.

* It was explained in the previous paper $(l . c$. pp. 584,585$)$ how the most effective primary capacity in any such case can be calculated. 
Fig. 1.

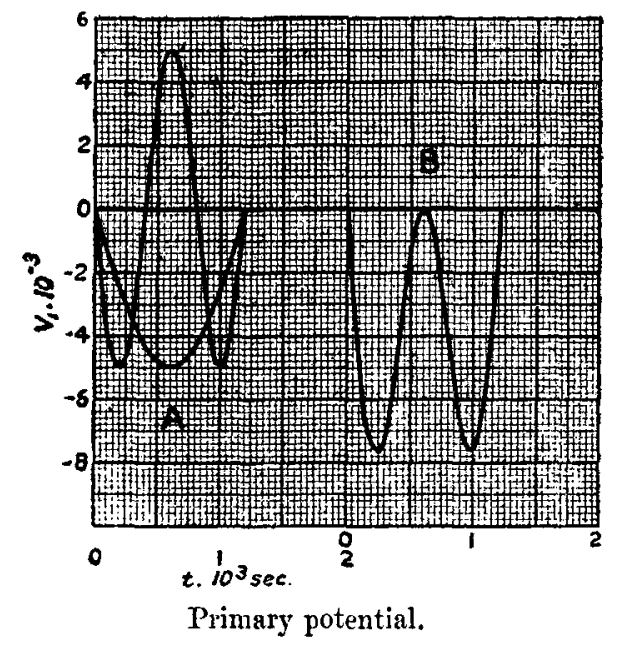

The curves in fig. 1 cover one half-period of the longer wave; their continuation in the second half-period is merely a repetition with the ordinates reversed in sign.

Fig. 2.

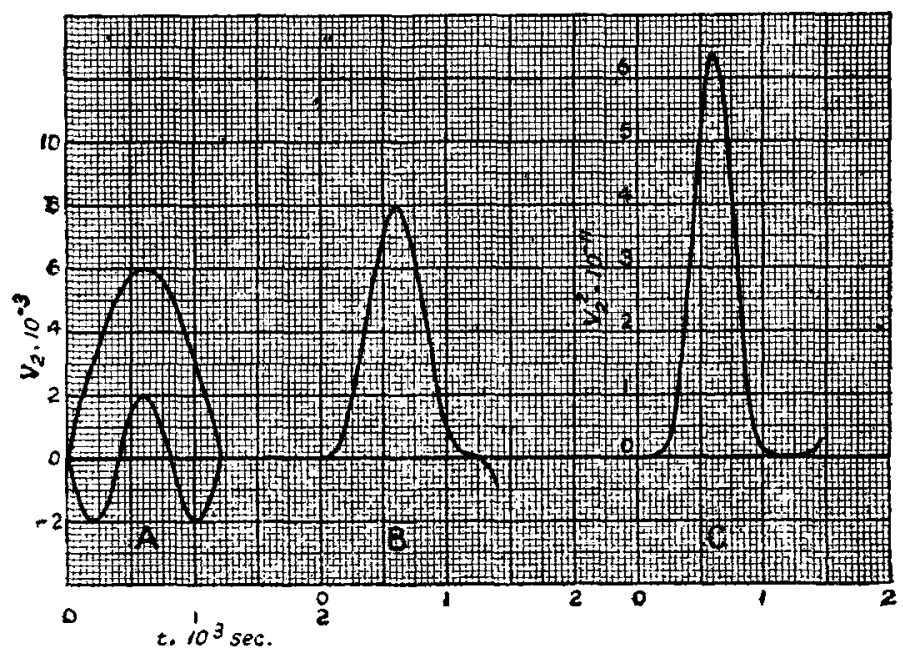

Secondary potential.

Fig. 2 (A) shows the corresponding potential wares in the secondary circuit; fig. 2 (B) the effect of their superposition. The amplitudes here are taken as 600,000 and 200,000 volts 
respectively. It will be seen that the two positive maxima coincide at $\cdot 0006$ sec. after the interruption, giving the maximum potential of 800,000 volts at the secondary terminals. At this moment the potential of the primary condenser is zero. Fig. 2 (C) shows (for comparison with the oscillograph surves described below) the curve obtained by squaring the ordinates of fig. 2 (B).

The above theoretical conclusions apply strictly only to the case of an ideal induction-coil, in which the resistances of the circuits and other causes of damping of the oscillations are negligible. Some applications of the theory were, lowever, given, in the former paper referred to *, in which it was shown that the results of the theory agree closely with experiment in so far as they concern the conditions under which the greatest spark-length is given by an induction-coil. The value of the secondary potential is of conrse greatly modified by the damping.

Another experiment will now be described, from the results of which some further information may be gathered as to the working of an induction-coil when in its most effective adjustment.

The coil experimented upon was the one employed in the previous experiments, viz.: an 18-inch coil in which the coefficient of coupling of the primary and secondary coils (the secondary terminals being connected to the oscillograph and to a variable spark-gap) is $\mathbf{8 7 6}$. The primary circuit was fed by a number of storage-cells, and included an amperemeter, a rheostat, and a slow interruptor which broke the current about once per second. The condenser was comnected directly across the interruptor.

The experiment consisted in increasing the self-inductance of the primary circuit by the addition of air-core coils, and varying the capacity of the condenser, until the longest, spark was produced by a given primary current. The curvo of secondary potential was then photographed, and the constants of the circuits determined. The best effect was found to be obtained with four extra coils in the primary circuit, and with a condenser of $\cdot 2$ microfarad capacity. It was not very easy to decide with great exactness upon the best selfinductance and capacity, owing to the fact that the sparklength varies slowly with these quantities in the neighbourhood of the maximum. A difference of $025 \mathrm{mfd}$. either way in $C_{1}$ caused no appreeiable change in the spark-length. From the practical point of view this slow variation near the maximum is in itself no disadvantage, since very exact

* L. c. pp. 582-586. 
adjustment is not necessary in order to produce a sparklength practically equal to the maximum.

The constants of the circuits were measured by methods which were fully described in the previous paper, and found to be as follows :-

$$
\begin{aligned}
\frac{1}{\mathrm{~L}_{1} \mathrm{C}_{1}} & =19 \cdot 57.10^{6} \text { c.G.s. } \\
\frac{1}{\mathrm{~L}_{2} \mathrm{C}_{2}} & =8 \cdot 763.10^{6} \quad, \\
k & =\cdot 748, \\
\mathrm{~L}_{21} & =20 \cdot 4 \text { henries, } \\
\frac{\mathrm{R}_{1}}{\mathrm{I}_{1}} & =680, \\
\frac{\mathrm{R}_{2}}{\mathrm{~L}_{2}} & =825 .
\end{aligned}
$$

$R_{0}$, the resistance of the primary circuit for steady currents, was 8 ohms.

Hence

$$
\begin{aligned}
& \theta_{1}=\frac{1}{2} \mathrm{R}_{1} \mathrm{C}_{1}=1 \cdot 738 \cdot 10^{-5} \text { c.G.s. } \\
& \theta_{2}=\frac{1}{2} \mathrm{R}_{2} \mathrm{C}_{2}=4 \cdot 709 \cdot 10^{-5}, " \\
& \theta_{0}=\frac{1}{2} \mathrm{R}_{0} \mathrm{C}_{1}=8 \cdot 10^{-7}, "
\end{aligned}
$$

The quantities $R_{1} / L_{1}, R_{2} / L_{2}$, were determined from the decay factors of the circuits when oscillating separately. The effective resistances $R_{1}, R_{2}$, are much greater than the steady-current values; they depend also upon losses due to leakage, hysteresis, and absorption. A considerable part of $\mathrm{R}_{2}$ is probably due to leakage through the electrometer. 'The decay factors are not consiant; the values of $R_{1} / L_{1}, R_{2} / L_{2}$ given above prevail during oscillations of fairly large amplitude in the primary and secondary circuits respectively.

The calculated frequencies are :

giving

$$
\begin{aligned}
& n_{1}=413 \cdot 9, \\
& n_{2}=1208,
\end{aligned}
$$

Also

$$
u_{2} / n_{1}=2 \cdot 919 \text {. }
$$

while

$$
\begin{aligned}
\mathrm{L}_{1} \mathrm{C}_{1} / \mathrm{L}_{2} \mathrm{C}_{2} & =\cdot 448 \\
1-k^{2} & =\cdot 440 .
\end{aligned}
$$

The differences between these values and those of the ideal case $\left(n_{2} / n_{1}=3, k=756, \mathrm{~L}_{1} \mathrm{C}_{1} / \mathrm{L}_{2} \mathrm{C}_{2}={ }^{*} 429\right)$ are within the limits of experimental error, and may be due to the above-mentioned difficulty of adjusting $L_{1}$ and $C_{1}$ accurately 
Effective Adjustment of an Induction-coil.

to give the best effect. If $L_{1}$ and $C_{1}$ were reduced, by amounts which would cause no appreciable change in the spark-length, the differences would disappear.

From the above data the secondary potential can now be calculated *, and the result, expressed in volts for $i_{0}=10$ amperes, is

$$
\begin{aligned}
V_{2} & =601300 \cdot e^{-266 t} \sin (149000 t-1 \cdot 95)^{\circ} \\
& -206900 \cdot e^{-1440 t} \sin \left(435000 t-5^{\circ} 7\right)^{\circ} .
\end{aligned}
$$

From this expression values of $V_{2}$, the difference of potential at the secondary terminals $t$ seconds after the interruption of the primary current, were calculated for

Fig. 3.

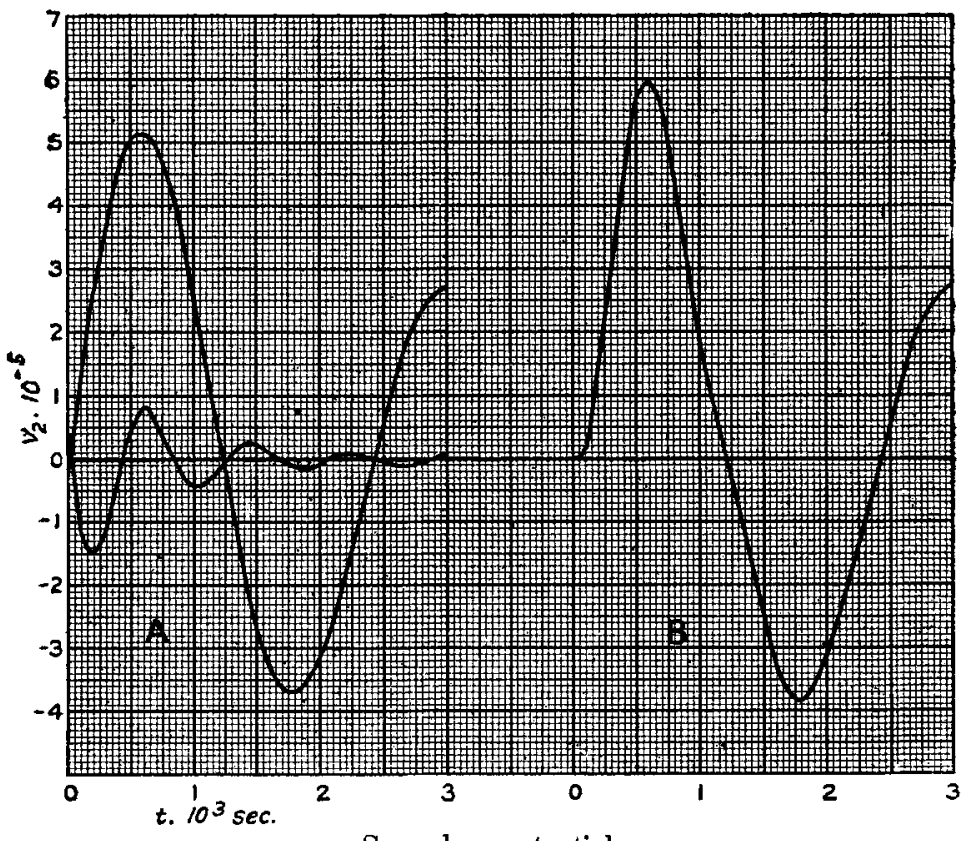

Secondary potential.

various values of $t$ up to .003 second, a time covering rather more than one whole period of the longer wave. The results are exhibited in fig. 3 , in which (A) shows the two oscillations

* The general expression for $\mathrm{V}_{2}$ is given in the previous paper, l.c. pp. 565, 574. The statement in the footuote on p. 574 requires correction. When the condenser is connected directly across the interruptor, so that the battery (e.m.f. E) is included in the primary oscillating circuit, wo have initially $V_{1}=0$, but fually $V_{1}=-E$. The results as given on pp. 574, 575, apply to this case provided $V_{1}$ is taken as $E$ +the potentialdifference of the primary condenser. 
of the secondary circuit separately, and (B) the result of their superposition. It will be seen that two positive maxima in the oscillations agree at about $t=.0006 \mathrm{sec}$, giving rise to the maximum secondary potential (596900 volts) at this time. Fig. 4 shows the square of the secondary

Fig. 4.

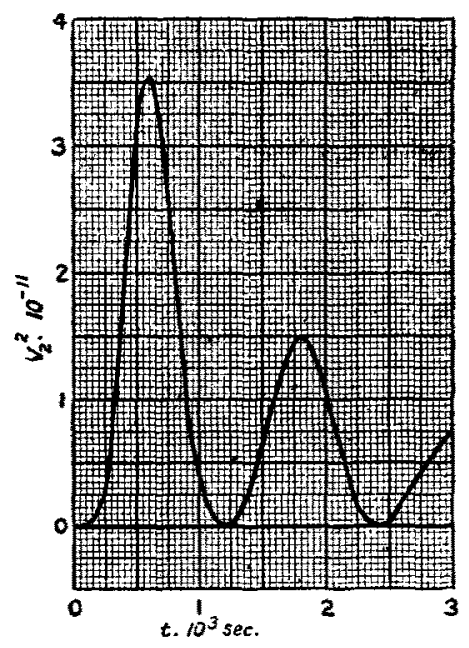

Square of secondary potential.

potential plotted against the time. This curve shows clearly the peaked maxima and the flattened zeroes which are characteristic of the $3 / 1$ ratio.

In Plate I. figs. 6 and 7 are shown photographic records of the secondary potential wave obtained with the oscillograph. In these curves the ordinates are proportional to the square of the secondary potential, owing to the idiostatic connexion of the instrument, and these curves are therefore directly comparable with fig. 4. The currents interrupted when these photographs were taken were 1.5 and $2 \cdot 0$ amperes respectively ${ }^{*}$. It will be seen that the greatest ordinates of the curves are proportional to the squares of the currents. In period $t$, rate of decay, and form the calculated curve of fig. 4 agrees well with the photographs. The photographic curves are perlaps rather more

* The greatest spark-length for 2 amperes, between spark-balls $2 \mathrm{~cm}$. in diameter, was $18.2 \mathrm{~cm}$. The external inductance being removed, and the primary coil being still in its symmetrical position within the secondary, the greatest spark-length at 2 amperes $\left(\mathrm{C}_{1}=0.6 \mathrm{mfd}\right.$.) was $12 \cdot 8 \mathrm{~cm}$. No sparks passed when the photographs shown were taken.

+ The time curre shown on the photographs has a period of $1 / 768 \mathrm{sec}$. 
peaked at the summits, and more flattoned at the zeroes, than the calculated curve, which indicates that the calculated damping factor of the shorter wave is rather too great in comparison with that of the slower oscillation. This may possibly be due to the existence of an appreciable difference (arising from various causes) between the values of the effective resistances of the circuits when oscillating separately, and their values when the circuits are oscillating as a coupled system.

'lurning now to the primary circuit, Dibbern's formula allows the potential wave in the primary condenser to be calculated *. Using the vilues given above for the constants of the circuits, and taking $i_{0}$, the primary current interrupted, as 10 amperes, Dibbern's expression becomes in the present case

$$
\begin{aligned}
\mathrm{V}_{\mathrm{I}} \dagger= & -5020 e^{-266 t} \sin (149000 t+8 \cdot 02)^{\circ} \\
& -4940 e^{-1440 t} \sin (435000 t-9 \cdot 07)^{\circ}, . .
\end{aligned}
$$

where $V_{1}$ is the primary potential in rolts.

The amplitudes of the two oscillations in the primary circuit are thus nearly equal, as required by condition (2).

The two oscillations represented by (4) are shown in fig. 5 (A), the result of their superposition in fig. 5 (B). It will be seen that the negative potentialf of the primary condenser: reaches a maximum of 6800 volts at about $\cdot 00025$ sec., and a minimum of 2250 volts at about $\cdot 00065$ sec. after the interruption. Thus, at the moment at which the secondary potential reaches its greatest value the primary condenser, instead of being uncharged as would be the caso in an ideal induction-coil, is still charged to about 2250 rolts, and this is due almost entirely to the difference in the damping factors of the two oscillations.

The effective resistances of the circuits therefore act in two ways in reducing the efficiency of the arrangement. First, they give rise to dissipation of energy and consequent decay of the amplitudes of both oscillations. Second, owing to the difference hetween the damping factors of the two oscillations, there is some energy stored in the primary condenser at the moment when the secondary potential is at its maximum.

* The existence of the two oscillations in the primary circuit after the interruption is well shown by a current oscillogram taken by WertheimSilomonson, Physit. Zeitschr, xi. p. 539, fig. 1 (1910).

+ As explained in the footnote on $\mathrm{p} .9$ abore, $V_{1}$ here means $\mathrm{E}+$ the potential of the condenser. $\mathbf{E}$ is here 80 volts.

+ The potential of the primary condenser is taken negative when it opposes the battery E.M.F. 
The efficiency is easily calculated in the present case. The maximum secondary potential, for $i_{0}=10$ amperes, is 596900 volts. If the resistances were negligible, and if the system

Fig. 5.

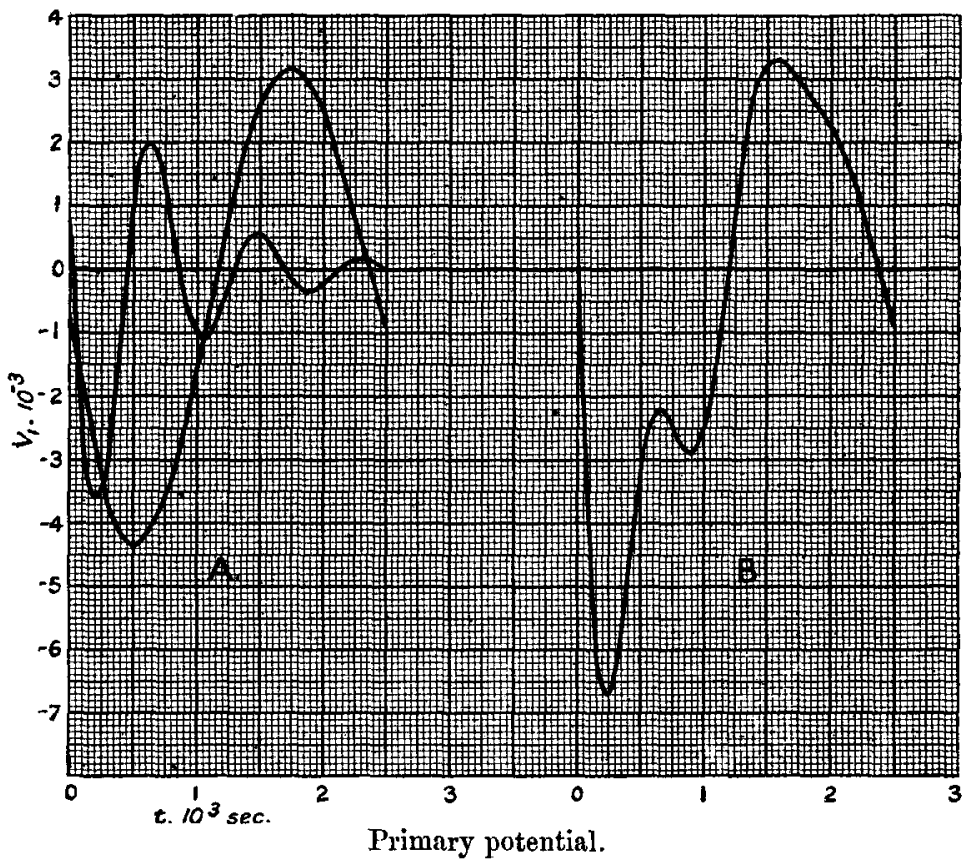

were exactly in the first unit-efficiency adjustment, the maximum secondary potential would be, by $(3 a), 798700$ volts. Consequently the efficiency is $\left(\frac{5969}{7987}\right)^{2}=\cdot 559$.

The energy originally in the system is $\frac{1}{2} \mathrm{~L}_{1} i_{0}{ }^{2}, i$. e. since $\mathrm{L}_{1}$ is about $\cdot 255$ henry, $12 \cdot 75$ joules. The maximum electrostatic energy in the secondary circuit is therefore $559 \times 12.75$, or about $7 \cdot 1$ joules. The energy then stored in the primary condenser (capacity $\cdot 2 \mathrm{mfd}$.) is $\frac{1}{2} \cdot \cdot 2.2250^{2} .10 \mathrm{ergs}$, or about $\cdot 5$ joule.

Consequently of the original $12 \cdot 75$ joules rather over 5 are dissipated, balf a joule is stored in the primary condenser, and the remaining 7 joules are available to provide for the secondary discharge at the moment of maximum potential.

The charge then on the secondary is $\mathrm{C}_{2} \mathrm{~V}_{2}$ and may be calculated when the capacity $\mathrm{C}_{2}$ is known. If we knew the value of the matio $\mathrm{L}_{21} / \mathrm{L}_{12}$ the capacity could be at once 
determined from the known values of $k^{2}, \mathrm{~L}_{1}, \mathrm{~L}_{21}$, and $\mathrm{I}_{2} \mathrm{C}_{2}$, since

$$
\mathrm{C}_{2}=\frac{\mathrm{L}_{21}}{\mathrm{~L}_{12}} \cdot \frac{\mathrm{L}_{1}}{\mathrm{~L}_{21}^{2}} \cdot k^{2} \cdot \mathrm{L}_{2} \mathrm{C}_{2} . \quad . \quad . \quad .
$$

With regard to the ratio $L_{21} / L_{12}$, this differs from unity because the current in the secondary coil during the oscillations is not uniformly distributed, but is greatest at the central winding and nearly zero at the ends. If all the windings of the secondary had equal inductive effects on the primary, when reckoned per unit current, and if the current in a turn of the secondary at a distance $z$ from the central winding were proportional to $\cos \frac{\pi z}{h}$, where $h$ is the length of the secondary coil, it is easily seen that $L_{21} / L_{12}$ would be equal to $\pi / 2$. In the actnal case, however, the inductive effect of the secondary windings (per unit current) diminishes from the centre towards each end. This was tested by ballistic galvanometer experiments in which the mutual inductance of the primary and a single turn of wire, wound on the secondary (or primary) in various positions, was compared with its value for the central position. From the results of these measurements it was found that this mutual inductance could be represented approximately by the expression $a-b z^{2}-c z^{4 *}$. Consequently $\mathrm{L}_{12}$ is proportional to

$$
\int_{-h / 2}^{+\pi / 2}\left(a-b z^{2}-c z^{3}\right) \cos \frac{\pi z}{h} d z
$$

while $L_{21}$ is proportional to

$$
\int_{-h / 2}^{+h / 2}\left(a-b z^{2}-c z^{4}\right) d z
$$

since the current in the primary coil is uniformly distributed. The value of $\mathrm{L}_{21} / \mathrm{L}_{12}$ is thereby reduced from $\pi / 2$, and becomes in the present case $\cdot 95 \pi / 2$.

Another correction is necessary if, as in the present experiments, the secondary terminals are connected to a capacity which is not negligible in comparison with that of the coil. In this case the secondary current is not quite zero at the ends of the coil, but should be represented as proportional to $\cos \frac{\pi z}{h^{\prime}}$, where $h^{\prime}$ is greater than $h$. The value

* The dimensions of the coils are:-primary, length $90 \mathrm{~cm}$, mean diameter $6.9 \mathrm{~cm}$.; secondary, length (between the terminals) $51 \mathrm{~cm}$., diameter (uutside) $24 \mathrm{cu}$. 
of $h^{\prime}$ may be estimated if we know the ratio of the external capacity $\mathrm{C}_{e}$ to the total capacity $\mathrm{C}_{2}$. If $\mathrm{C}_{e}$ is small in comparison with $\mathrm{C}_{2}$ the approximate value of the latter (obtained from equation (5) by neglecting the present correction) may be used here. If the current in the secondary windings varies as $\cos \frac{\pi z}{h^{1}}$, the charge per unit length will be proportional to $\sin \frac{\pi z}{h^{\prime}}$. Hence the ratio of $\mathrm{C}$ to $\mathrm{C}_{\mathrm{z}}$ is equal to the ratio of

$$
\begin{aligned}
& \int_{h 2}^{h^{\prime} 2} \sin \frac{\pi z}{h^{\prime}} \cdot d z \quad \text { to } \quad \int_{0}^{h^{\prime} 2} \sin \frac{\pi z}{h^{\prime}} d z \\
& \text { i. e. } \quad \frac{\mathrm{C}_{e}}{\mathrm{C}_{2}}=\cos \frac{\pi h}{2 h^{\prime}} .
\end{aligned}
$$

This determines $h^{\prime} / h$, and we then have

$$
\begin{aligned}
\frac{\mathrm{L}_{12}}{\mathrm{~L}_{21}} & =\frac{1}{h} \int_{-h / 2}^{+h_{2} 2} \cos \frac{\pi z}{h^{\prime}} d z \\
& =\frac{2}{\pi} \cdot \frac{h^{\prime}}{h} \cdot \sin \frac{\pi h}{2 h^{\prime}} .
\end{aligned}
$$

In the present experiments $\mathrm{C}_{e}$ is the capacity of the electrometer and the spark-gap terminals, and this is about one-sixth of the total secondary capacity $\mathrm{C}_{2}$, the value of which is already known approximately. Hence $\cos \frac{\pi h}{2} l^{\prime}=\frac{1}{6}$, and $\frac{h^{\prime}}{h}=1 \cdot 12$, from which $\frac{\mathrm{L}_{12}}{L_{21}}=1 \cdot 10 \cdot \frac{2}{\pi}$. The effect of this correction is therefore further to reduce $\mathrm{L}_{21} / \mathrm{L}_{12}$ by about 10 per cent.

Taking both corrections into account we have approximately

from which by (5)

$$
\mathrm{L}_{21} / \mathrm{L}_{12}=\cdot 85 \pi / 2=1 \cdot 335 \text {, }
$$

$$
\mathrm{C}_{2}=\cdot 000052 \text { microfarad. }
$$

The charge of the secondary circuit at the moment of maximum potential is therefore $5 \cdot 2 \times 5.969 \times 10^{-7}$ C.G.S., or $31 \cdot 10^{-6}$ coulomb. If the whole of this charge escaped from the terminals, in the form of a spark or other discharge, the discharge current would be, at $n$ interruptions per second, $n \mathrm{C}_{2} \mathrm{~V}_{2}$. Further experiments are, however, required in order to decide whether this complete discharge takes place, or whether some of the electricity does not return through the secondary coil and continue to oscillate in it. 
The conditions for maximum potential are the same when a rapid interruptor is employed as for the slow break used in the above experiments. They also hold whether the primary current is supplied by a small storage-battery, a 100-volt battery, or the 200-volt mains. Plate I. fig. 8 shows the course of the secondary potential at two successive "brealss" effected by a motor mercury interruptor. 'The effect of the small potential at the "make" is also noticeable. On this occasion the 100-volt battery was used to supply the primary current, the total (steady-current) resistance in the primary circuit, being 11 ohms. The greatest spark-length was $18.4 \mathrm{~cm}$, and the mean primary current, as indicated by an amperemeter in the primary circuit, was $\cdot 3$ ampere. The current immediately before interruption would, however, be over 2 amperes.

Bangor, November 1914.

II. On Motion in a Periodic Field of Force. By C. V. RAMAX, M.A.*

[Plate II.]

Vibrations maintained by a Periodic Field of Force.

THE experimental study of the motion of a dynamical 1 system in a periodic field of force leads to results of quite exceptional interest. One aspect of the problem, $i . e$. the oscillatory motion of the system about a position of equilibrium in the field, has some affinities to the case of vibrations maintained by a variable spring which I have dealt with in my previously published work, but the two classes of investigations lead to results which differ from one another, yet are related in a most remarkable way. By experimenting on stretched strings subjected to a variable tension, I showed that a normal variation of spring will enable the oscillations of the system to be maintained, when the frequency of these oscillations is sufficiently nearly equal to $\frac{1}{2}$ of, or $\frac{2}{2}$ times, or $\frac{3}{2}$ times, or $\frac{4}{2}$ times, \&c. the frequency of variation of the spring, these ratios forming an ascending series $\dagger$. By experiments on the vibrations of a body about a position of equilibrium in a periodic field of force (to be described below), I have shown that the frequency of the oscillations maintained may be equal to, or half of, or one-third, or onefourth, \&c. of the frequency of the field; in other words, it

* Communicnted by the Author.

+ See Phil. Mag. Oct. 1912, "The Maintenance of Forced Oscillations of a New Type." 
E. T. JONES.

Phil. Mag. Ser. 6, Vol. 29, Pl. I.

FIG. 6.

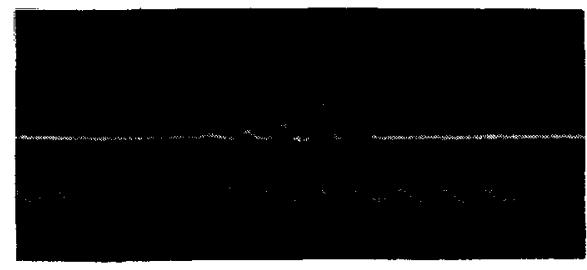

Primary current 1.5 amperes.

Fig. 7 .

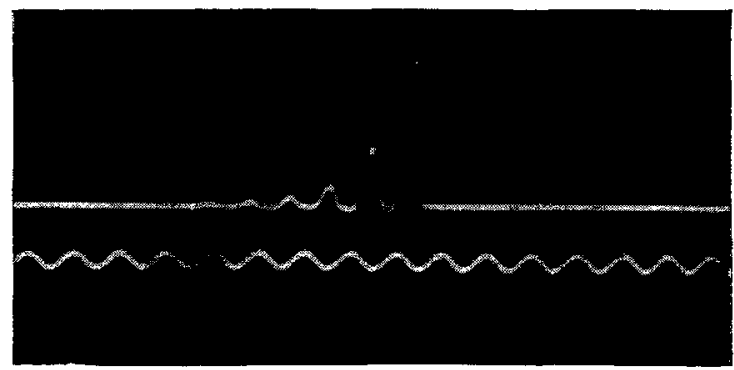

Primary current 2 amperes.

Fict. 8.

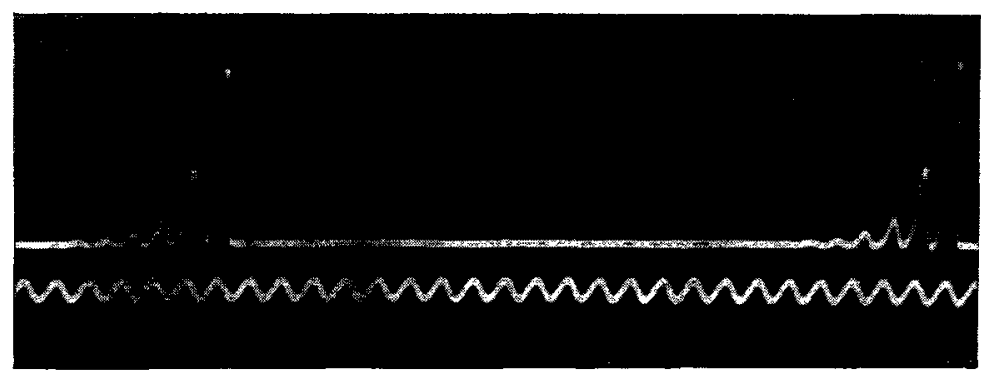

Two successive breaks by motor interruptor. 